\title{
Current Diagnosis and Management of Hypersensitivity Pneumonitis
}

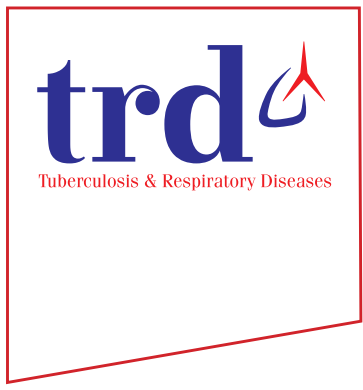

\author{
Paolo Maria Leone, M.D. ${ }^{1,2}$ and Luca Richeldi, M.D., Ph.D. ${ }^{1,2}$ (i) \\ ${ }^{1}$ Fondazione Policlinico Universitario A. Gemelli IRCCS, Rome, ${ }^{2}$ Università Cattolica del Sacro Cuore, Rome, Italy
}

Hypersensitivity Pneumonitis (HP) one of the most common interstitial lung diseases (ILDs) is characterized by exposure to an inhaled inciting antigen that leads to a host immunologic reaction determining interstitial inflammation and architectural distortion. The underlying pathogenetic mechanisms are unclear. The absence of international shared diagnostic guidelines and the lack of a "gold-standard" test for HP combined with the presence of several clinical and radiologic overlapping features makes it particularly challenging to differentiate HP from other ILDs, also in expert contests. Radiology is playing a more crucial role in this process; recently the headcheese sign was recognized as a more specific for chronic-HP than the extensive mosaic attenuation. Several classification proposals and diagnostic models have been advanced by different groups, with no prospective validation. Therapeutic options for HP have been limited to antigen avoidance and immunosuppressant drugs over the last decades. Several questions about this condition remain unanswered and there is a need for more studies.

Keywords: Hypersensitivity Pneumonitis; Lung Diseases, Interstitial; Fibrosis; Diagnosis; Management; High Resolution Computed Tomography; Therapy; Steroids; Antigens; Nintedanib; Pirfenidone

\section{Introduction}

Hypersensitivity pneumonitis (HP), also known as extrinsic allergic alveolitis, is one of the most common interstitial lung diseases (ILDs) ${ }^{1,2}$. This particular ILD is characterized by exposure to an inhaled inciting antigen that leads to a host immunologic reaction determining interstitial inflammation and architectural distortion. The underlying pathogenetic mechanisms are still unclear, showing features of both type III and type IV hypersensitivity responses ${ }^{3,4}$. The sensitization

Address for correspondence: Paolo Maria Leone, M.D.

UOC Pneumologia, Fondazione Policlinico Universitario A. Gemelli

IRCCS, Largo A. Gemelli 8, 00168 Rome, Italy

Phone: 39-06-3015-6202, Fax: 39-06-3015-8011

E-mail: paolomaria.leone@gmail.com

Received: Feb. 14, 2020

Revised: Feb. 18, 2020

Accepted: Feb. 19, 2020

Published online: Mar. 10, 2020

(c) It is identical to the Creative Commons Attribution Non-Commercial License (http://creativecommons.org/licenses/by-nc/4.0/). process to the inciting antigen plays a pivotal role, turning a two-hit hypothesis in the most probable one (Figure 1).

HP epidemiology results to be challenging to determine considering the influence of many host, geographic and social factors ${ }^{5}$, also few cohort studies are reported in literature. But recently a one-year prevalence of 1.67-2.71 per 100,000 persons and a 1-year cumulative incidence of 1.28-1.94 per 100,000 persons were reported in a large American population ${ }^{6}$. With a $28 \%$ of 4 -year mortality and a $52 \%$ of 7 -year mortality fibrotic- $\mathrm{HP}^{6}$, the form with the worst prognosis, shows to have a better prognosis than idiopathic pulmonary fibrosis (IPF) ${ }^{7.8}$, but still a worse one when compared to some neoplastic conditions, such as thyroid, prostate and colorectal cancer'.

Furthermore, the absence of widely shared diagnostic guidelines and the lack of a "gold-standard" test for HP combined with the presence of several clinical and radiological overlapping features makes it particularly challenging to differentiate $\mathrm{HP}$ - mostly in its chronic and fibrotic form-from other ILDs, such as IPF ${ }^{10}$.

Therapeutic options for HP were limited to immunosuppressant drugs in the last decades, but recently the effect of nintedanib and pirfenidone has been tested with promising results in patients with chronic-HP (cHP).

This review aims to clarify the current state of the art of diag- 
A Sensitization and immune memory formation

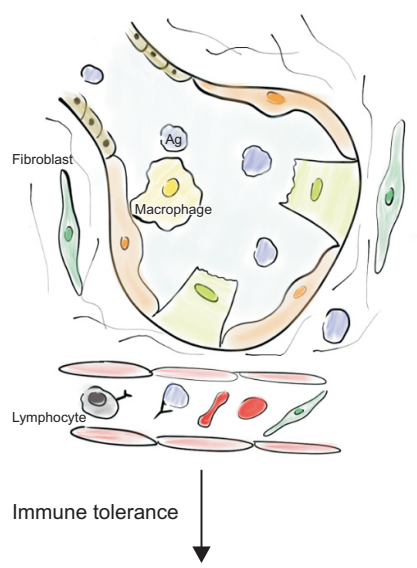

Normal response
B Acute/subacute inflammation

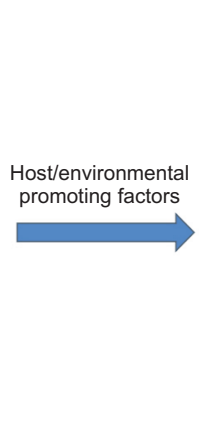

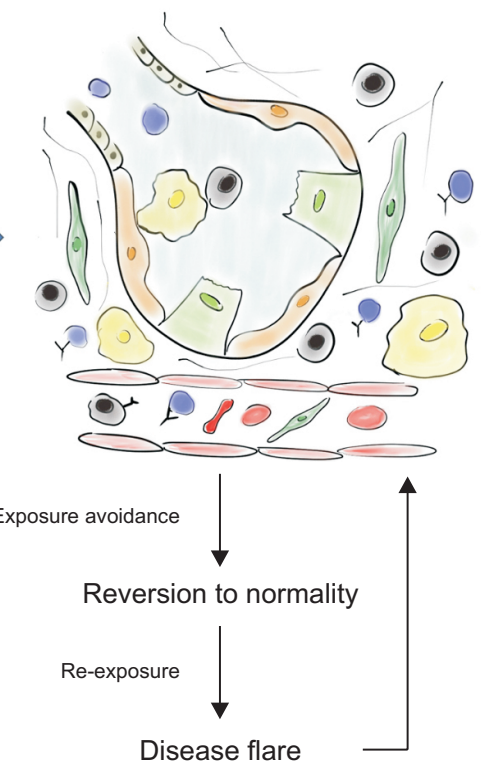

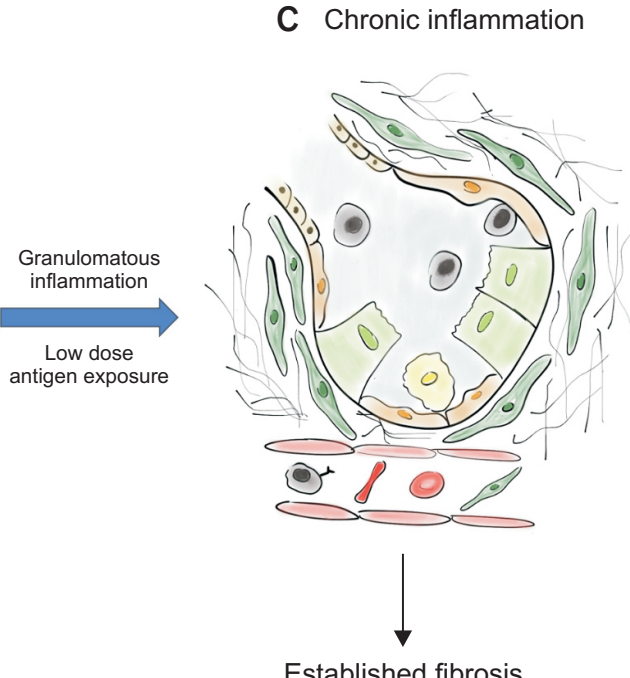

Figure 1. Immune response in Hypersensitivity Pneumonitis. Characterized by sensitization and immune memory formation (A), acute/subacute inflammation (B), and chronic inflammation (C).

nosis and management of HP.

\section{Diagnosis}

\section{Medical history and antigen exposure}

HP seems to affect more often non-smoker elderly women ${ }^{6}$, even if epidemiologic data are contrasting, mostly regarding gender prevalence ${ }^{2,11-13}$. Several cases were reported also in children $^{14}$ and among teenagers accustomed to vaping ${ }^{15}$. Cigarette smoke seems to have a double role in HP, it protects from developing the disease ${ }^{16}$, but if there is a positive smoking history it worsens the prognosis ${ }^{17}$. Several studies also reported a male predominance among HP subjects ${ }^{2,11-13}$.

Furthermore, other host factors may play a role in HP developing process. Just a minority of the subjects exposed to inciting antigens develop the disease, proofing that some sort of genetic predisposition is involved in the process ${ }^{18-21}$. Lopez and Salvaggio ${ }^{22}$ showed that just 5\%-15\% of the subjects with known exposure to inciting agents developed HP.

Another fundamental factor is the host work-related exposure. HP was firstly reported as Farmer's Lung in the early decades of the 20th century, making it clear that some class of workers are more prone to develop this disease. Among the others, we may find farmers, machinists, factory workers, and pigeon breeders ${ }^{23}$. Other environmental exposures, such as the possession of a pet-bird or an indoor hot-tub, significantly increase the likelihood of HP diagnosis. The main classes of inciting antigens are bacteria, fungus, mycobacteria, avianproteins, and chemical products.

HP symptomatology is aspecific and overlaps with several conditions, being characterized by shortness of breath, acute or slightly worsening, dry cough, malaise, fatigue, loss of appetite, chills, fever, etc.

Historically HP was classified into three categories acute, subacute and chronic; this classification was based both on symptoms behavior and disease course. While a recently proposed one, in order to solve some phenotype's overlap mostly between the subacute and the chronic form, promotes the presence of only two categories: the acute/inflammatory HP (aHP) and the chronic/fibrotic (cHP) $)^{24,25}$.

Influenza-like symptoms (i.e., fever, chills, cough, acute dyspnea, etc.) are more common in aHP; symptomatology usually begins a few hours following the antigen exposure and it may both last or increase over hours or days ${ }^{23,25}$. Similarly to what happens in working-related asthma, in aHP symptoms mostly decrease in presence and intensity after a suitable period of avoidance of the exposure and may proof, in this way, a causal link between expositions and symptomatology.

While cHP is characterized by a sneaky debut of symptoms characterized by slightly worsening dyspnea, dry chough, malaise, fatigue, loss of appetite ${ }^{23,25}$, that makes this form of the disease on a clinical standpoint very similar to other fibrotic ILDs and particularly similar to IPF. Repetitive and low-dose antigen exposure is the most common cause of $\mathrm{cHP}$ forms ${ }^{26}$.

The research of an inciting antigen may often be tricky: the percentage of cases with successful identification of the caus- 
ative antigen stands below $40 \%^{27}$. Several methods were suggested in order to find it, such as questionnaires, precipitins, lymphocyte proliferation test and specific inhalation challenge (SIC), but none of those reached large consensus ${ }^{28}$. These methods present limited availability, lack of standardization and some of them may result in pretty expensive. There is also restricted amount of information about tests' characteristics, mostly regarding SIC.

\section{Pulmonary function tests}

Pulmonary function tests (PFTs) - as for every ILD—may reveal functional impairment and guide clinicians through patient management. Global spirometry and diffusing capacity of carbon monoxide (TLCo) are useful non-invasive methods to determine disease course and loss of lung function. TLco and forced vital capacity (FVC) decline over time are predictive factors of survival in HP patients ${ }^{29,30}$. TLco particularly may predict exercise impairment being the most sensitive functional abnormality ${ }^{31,32}$. HP-related histologic changes, indeed, reduce gas exchange's area and influence pulmonary distension. A >10\% FVC decline over 6-12 months showed to be a good predictor of worse prognosis ${ }^{33}$. However, when fibrosis is present, PFTs may be insensitive to detect small airway involvement ${ }^{34}$.

Both aHP and cHP are characterized by gas exchange impairment ${ }^{35,36}$.

Besides the acknowledged utility, PFTs may not differentiate HP from the other ILDs ${ }^{37}$.

\section{Radiology}

Nowadays high resolution computed tomography (HRCT) plays a role of growing interest in HP diagnostic process and patient management. It is also recognized as the tool capable to identify HP findings with the highest sensitivity ${ }^{34}$.

The main findings of aHP are multifocal and diffuse groundglass opacities (GGO), centrilobular GGO, signs of air trapping on expiratory phases studies and "headcheese sign." This last sign is characterized by the contiguity of lobular areas with different attenuation levels (low, normal or high), which reflect heterogenous processes such as GGO, reticulation or fibrosis (high attenuation), normal parenchyma (normal attenuation) and air trapping (AT) (low attenuation) $)^{38}$.

The heterogeneity of HP, with both obstructive processes (small airways' obstruction) and infiltrative ones (interstitial phlogosis) ${ }^{38}$, is exemplified by the headcheese sign (Figure 2) and mosaic attenuation (MA). HRCT is useful to identify localized disease-related impairments and airway involvement. Among the ILDs HP is the one that more extensively exhibits $\mathrm{MA}$, turning it into a prominent feature of $\mathrm{HP}^{39}$.

The main findings of cHP are architectural distortion, reticular opacities, peribronchovascular interstitial thickening, ill-defined centrilobular GGO, MA pattern, upper and middle zone predominance, sparing of basal lung areas and traction bronchiectasis, honey combing (HC) may be present (Figure $2)^{34}$. At its most advanced stages of disease cHP might show radiologic pattern hard to differentiate from either fibrotic nonspecific interstitial pneumonia (NSIP) or usual interstitial pneumonia (UIP) with HC. The differential diagnosis of HP with other ILDs might be tricky also because of these similari-
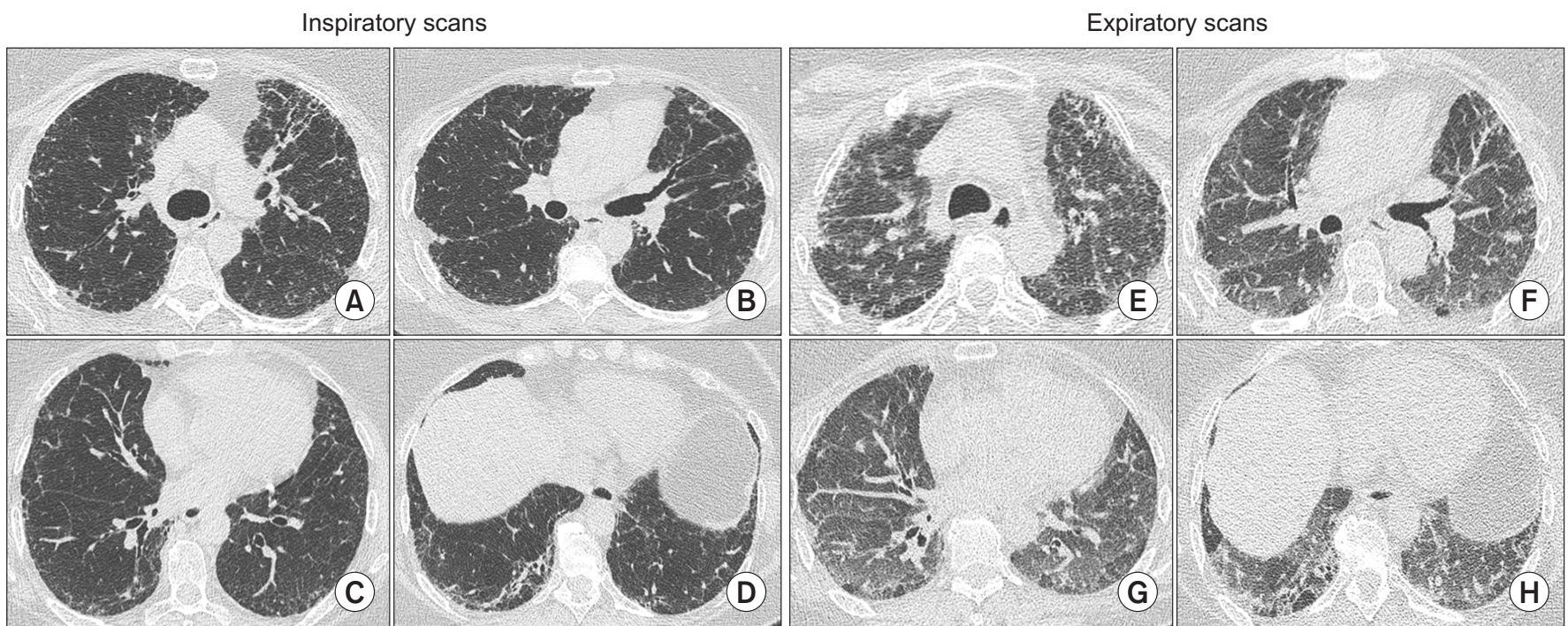

Figure 2. Radiologic appearance of chronic hypersensitivity pneumonitis at chest high resolution computed tomography. In the inspiratory scans (A-D) architectural distortion, reticular opacities, peribronchovascular interstitial thickening ground-glass opacities and traction bronchiectasis are evident. In the expiratory scans (E-H) the headcheese sign was found. 
ties $^{40-42}$, mostly in cases where there is no identification of the inciting antigen.

Rarer are the cases in which cysts and emphysema are recognized on the chest computed tomography scans of HP patients, but they are still possible radiologic features of this heterogenous condition ${ }^{43,44}$.

Recently great attention was put on radiologic features of HP with different studies focusing on HRCT prognostic and diagnostic role. The great majority of the studies used a qualitative approach ${ }^{34}$, opening the door analysis' bias.

Salisbury et al. ${ }^{45}$ developed a radiologic predictive model for HP diagnosis. Their analysis enlightened that when a major extension of AT and MA compared to that of reticulation is present, combined to a diffuse axial distribution, there is less than $10 \%$ chances to make a false-positive diagnosis of $\mathrm{HP}^{45}$. Silva et al. ${ }^{41}$ explored the role of HRCT in solving the challenge of differential diagnosis among HP, IPF, and other ILDs. A confident differentiation between these different entities was possible in nearly half of the cases, underlying once again how tricky it may be relying just on radiologic findings for differential diagnosis. Barnett et al. ${ }^{42}$ recently focused their attention on MA and its role in the differential diagnosis with IPF. The presence of the headcheese sign resulted a more confident feature to lead to differentiation between cHP and IPF than just the extension of MA, challenging the faith of the scientific community $^{42,46}$.

Some studies were performed in order to highlight the prognostic role of radiologic features in HP. Chung and coworkers showed how the presence of AT and MA in cHP subject may positively influence the survival ${ }^{47}$. Salisbury et al ${ }^{48}$ successfully identified three unique radiologic groups of HP patients with different prognostic outcomes. The presence of HC in cHP determined a prognosis superimposable to the IPF one, worse than the prognosis of patients with just cHP; as expectable, patients without fibrotic changes were the group characterized by the better prognosis ${ }^{48}$. This radiologic phenotypes seems easy to adopt and useful in stratifying HP patients ${ }^{49}$.

The quantitative analysis through the CALIPER software was the fundament of Jacob and coworkers' study ${ }^{50}$. This is one of the few studies relying on quantitative analysis methods in HP. The main findings of this work were that the automated analysis performed better than visual scores and was able to stratify HP population based on pulmonary vessel volume (PVV). Patients with cHP and a high PVV presented a prognosis similar to IPF patients ${ }^{50}$.

\section{Bronchioalveolar lavage}

The use of the bronchoalveolar lavage (BAL) technique is pretty common in the ILD field, even more after the release of the last guidelines for IPF diagnosis ${ }^{51}$. American Thoracic Society (ATS) already addressed this issue in 2012, when an official guideline about the clinical utility of BAL fluid (BALF) analysis in ILD was released ${ }^{52}$. BAL is often performed in HP patients both in the acute and in the chronic forms. Several studies reported data about BALF cellularity in these conditions ${ }^{30}$. By the way, it is still unclear the role of BAL both in HP diagnostic process and in HP patients' management.

Lymphocytosis is, doubtless, the BALF parameter more often taken into account in HP studies and diagnostic predictive models. A higher percentage of lymphocyte in BAL may be a positive predictor of HP diagnosis, even if a BALF lymphocytic profile may be found also in sarcoidosis, NSIP, and organizing pneumonia $^{52}$. Higher levels of lymphocytosis $(>30 \%-40 \%)$ seem to better correlate with aHP. While cHP may show a slightly increased lymphocytic count $(>20 \%)$ or even a normal one, mostly in patients with radiologic UIP ${ }^{53,54}$. Some authors argue that a higher lymphocytic count may be a positive predictive factor for survival, considering those forms of HP acute ones and more prone to disease resolution ${ }^{55}$ and response to corticosteroid treatment ${ }^{56}$. On the other hand, a BAL lymphocytosis $>30 \%$ seems to be a useful tool in the tricky differential diagnosis between cHP and IPF, making IPF diagnosis very unlikely in such a scenario ${ }^{57}$.

Besides all the efforts widely shared thresholds for BAL lymphocytosis have not been identified yet ${ }^{25,28}$.

Also the study of $\mathrm{T}$ cells population was carried on HP patients' BALF, but not definitive findings supporting its use in daily clinical practice have been made ${ }^{25,52}$. Patients with aHP seem to have a higher percentage of $\mathrm{CD}^{+}$, which lowers after exposure avoidance, at the same time patients with cHP seem to have a $\mathrm{CD} 4^{+}$predominance ${ }^{58,59}$. When talking about the CD4/CD8 ratio, a nonspecific and insensitive trend towards lower levels seems to characterize $\mathrm{HP}^{25,52,54}$.

\section{Histology}

The integration of clinical, radiologic and pathologic findings remains the gold standard for the diagnosis of every subtype of ILD, but recently we are moving toward a world where less invasive procedures are performed on patients. Constantly growing importance is given to radiologic features, that in several cases may guide clinicians to a confident diagnosis even in the absence of histopathologic specimens.

Surgical lung biopsy (SLB), as for the other ILDs, is the gold standard for tissue sampling ${ }^{60}$, besides complications related to this invasive procedure. Other systems like transbronchial biopsies and transbronchial criobiopsies have been proposed as alternatives, but no formal validation and/or international consensus was reached about their use in the diagnostic process of ILDs ${ }^{51,61,62}$.

Being HP a condition with heterogenous histologic alterations SLB providing a greater amount of tissue should probably be the elective tissue sampling procedure in order to have more chances to find the most characteristic lesions.

The classic histologic triad of HP is composed by peribron- 
chiolar diffuse interstitial inflammatory infiltrates, chronic bronchiolitis and peribronchiolar giant cells (with or without non-caseous and non-necrotic granulomas) (Figure 3$)^{63-65}$. In the latest stages of disease also UIP may be found.

Histology also plays a role in the prognostic stratification of HP subjects. The UIP pattern, when found, correlates with a worse prognosis ${ }^{29}$. Also airway centered fibrosis and fibrotic NSIP show a worse prognosis when compared to peribronchiolar inflammation with poorly formed granulomas and cellular $\mathrm{NSIP}^{66}$.

\section{Actual diagnostic models and lack of consensus}

Some predictive and diagnostic models were recently proposed to facilitate clinicians in the hard task represented by making a confident HP diagnosis ${ }^{24,25,28,37,67}$. None of them reached a wide consensus, but at least they aroused effervescent discussions about this topic ${ }^{68-71}$. And nowadays both the ATS and the American College of Chest Physicians (ACCP) are promoting initiatives aimed to draft clinical evidencebased guidelines for $\mathrm{HP}^{46,70}$.

Walsh and coworkers perfectly painted how challenging it may be reaching consensus about HP diagnosis ${ }^{72}$. In their study the inter-multidisciplinary team (MDT) agreement for HP diagnosis was incredibly poor, making it clear to everyone that even clinicians with a proven expertise in the ILD field may find it difficult to make HP diagnoses that meet the consensus of the other groups.

Furthermore, different groups of experts are also proposing different classifications of the disease making the HP field even more chaotic. We are all used to the historical classification with the three forms of HP: acute, subacute and chronic. That was recently overtaken by a more simplistic and binary one: aHP and cHP. This one, thus appearing too simple, seems to be useful ${ }^{30}$ and also supported by recent radiologic findings $^{48,49}$.

One of the key points of HP diagnosis, in patients with compatible respiratory symptoms, is the recognition of the inciting antigen. All the proposed diagnostic models agreed on that. A careful clinical history should be collected and it is fundamental for HP diagnosis, nevertheless in several cases the inciting antigen may remain elusive ${ }^{27}$. The IPF guidelines and Fleischner Society's White Paper also suggest as one of the very first steps of the diagnostic process to check for possible exposures in patients suspected to have IPF, being HP a possible alternative diagnosis ${ }^{51,73}$. Vasakova et al. ${ }^{25}$ developed an exhaustive questionnaire, but it is still lacking of formal validation. The same group of authors proposed the definition of "cryptogenic HP" for all those cases of truly unknown origin, but this terminology was strongly criticized ${ }^{70,74}$.

All the available diagnostic models also agree about the absence of a "gold standard" test for HP diagnosis. However, radiology is nowadays having a pivotal role in the diagnostic algorithm of ILDs and HP is not excluded. Radiologic findings may indeed guide the diagnostic process towards other steps, such as what happens in $\mathrm{IPF}^{24}$. Radiologic features like extensive MA were typically thought to be expression of HP: Fleischner Society's White Paper reported "extensive" MA as most consistent with cHP than $\mathrm{IPF}^{73}$, while the last international guidelines indicate that "marked" MA should arise the doubt of IPF alternative diagnosis ${ }^{51}$. However recently we witnessed an attempt to change of perspectives when the headcheese sign was proposed as specific for cHP and inconsistent with $\mathrm{IPF}^{42}$. The more relevant role undertaken by HRCT leads to a minor rate of invasive procedures' execution, similarly to what happens with IPF tissue sampling is always less common such as BAL. These procedures are often relegated to the more challenging cases when, lacking the inciting antigen's identification and typical radiologic pattern, the diagnosis' confidence is low.

As previously reported, lymphocytosis is a characteristic finding in HP patients, nevertheless no shared threshold for it has been defined yet. Morisset and coworkers in their modified DELPHI survey reported consensus among international
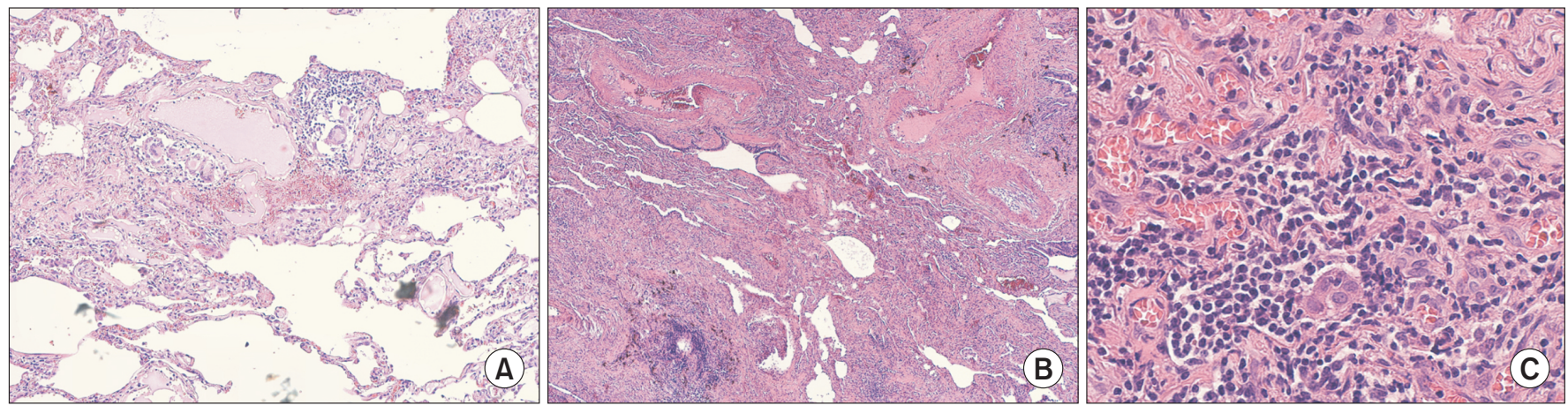

Figure 3. Histopathologic aspect of chronic Hypersensitivity Pneumonitis (cHP) at hematoxylin and eosin stain: fibrosis with micro-honeycombing, non specific chronic inflammation with peri-bronchial and centrilobular distribution (A, B) and multiple non-caseating giant cell granulomas (C). 
experts for high confidence HP diagnosis without the execution of lung biopsy in the right clinical contest (recognized exposure and HRCT consistent with cHP) when BAL lymphocytosis was $>40 \%^{28}$. While Salisbury et al. ${ }^{24}$ proposed a $20 \%-30 \%$ threshold in their diagnostic model, which is mostly focused on cHPs.

The integration of the information conveyed by clinical history, lab tests, PFTs, HRCT, BAL analysis, and histology should be processed and discussed by MDTs in order to decide the best diagnostic strategy and reach a confident diagnosis. The importance of MDTs is growing constantly in the ILD field and the evidence-based algorithm proposed by Salisbury et al. ${ }^{24}$ takes the move from an MDT evaluation and wisely proposes a pathway that aims to reach the highest diagnostic confidence using the less amount of invasive procedures possible.

\section{Treatment}

\section{Antigen avoidance and immunosuppressants}

Guidelines for HP treatment are not available at the moment. All the therapeutic regimens proposed to derive mostly from observational studies and very few randomized trials.

The recognition of the inciting antigen is useful not only for diagnostic purposes but also for patients' management. HP is recognized as a condition driven by a massive autoimmune response to inhaled antigens, then the first step of HP treatment is the antigens' avoidance, when possible. This is mostly effective in the early/acute phases of disease and less effective in the chronic forms of HP, when fibrotic changes intervene $^{27,69,75,76}$. Furthermore, in cHP fibrosis may progress even if the subjects are not exposed to the antigens anymore.

Another cornerstone of HP treatment is immunosuppres- sant treatment, for the same reason.

Corticosteroid treatment in HP is supported by weak evidence. There is just one randomized trial and it is short and small $^{77}$. The use of predinosolone tapered along 8 weeks against placebo was evaluated in cohort of 36 patients affected by Farmer's Lung. All the patients avoided contact with farms for the duration of the study. No differences were found in pulmonary function parameters, besides a significant difference in TLco. There was also no effect of corticosteroid treatment on mortality. Corticosteroids seem to be more effective on aHP when the phlogistic process is more abundant. Some other non-randomized trials and observational studies supported these findings ${ }^{75,76}$. De Sadeleer et al. ${ }^{76}$, in their retrospective study, showed that the steroid treatment had no benefit on cHP patients, while it was effective on lung function and mortality of aHP patients.

Other immunosuppressant therapies have been studied in HP patients, such as mycophenolate mofetil (MMF) and azathioprine $(\mathrm{AZA})^{78,79}$. Both treatment regimens seemed to be effective improving TLco in cHP patients in the study of Morisset et al. ${ }^{78}$, not showing any benefit on survival. The study conducted by Adegunsoye et al. ${ }^{79}$, instead, did not show any effect of both AZA and MMF on lung function. Nevertheless, cHP patients who needed to undergo immunosuppressant therapies showed a worse survival rate. However, an early transition to steroid-sparing drugs seems to reduce the incidence of treatment-emergent adverse events ${ }^{79}$. Rituximab is also sometimes used off-label as salvage treatment in refractory forms of $\mathrm{cHP}^{80}$.

Inhaled corticosteroid therapy is used on anecdotal basis ${ }^{81}$.

\section{Antifibrotics and future perspectives}

The prototype of the progressive fibrosing phenotype ILD is IPF, but this phenotype also develops in cHP. No matter what

Table 1. Clinical trials exploring anti-fibrotic drugs' role in cHP therapy

\begin{tabular}{|c|c|c|c|c|c|c|}
\hline Agent & Registration No. & Study design & Population & Aims & Primary end point & State \\
\hline Nintedanib & $\begin{array}{l}\text { NCT02999178 } \\
\text { (INBUILD) }\end{array}$ & $\begin{array}{l}\text { Phase III, randomized, } \\
\text { double blind, placebo- } \\
\text { controlled }\end{array}$ & Fibrosing ILDs & $\begin{array}{l}\text { Efficacy and } \\
\text { safety }\end{array}$ & $\begin{array}{l}\text { Annual rate of FVC } \\
\text { decline }\end{array}$ & $\begin{array}{l}\text { Completed, } \\
\text { published results }\end{array}$ \\
\hline Pirfenidone & NCT02496182 & $\begin{array}{l}\text { Phase II/III, placebo- } \\
\text { controlled, open-label, } \\
\text { proof of concept }\end{array}$ & $\mathrm{cHP}$ & $\begin{array}{l}\text { Efficacy and } \\
\text { safety }\end{array}$ & FVC over 52 weeks & $\begin{array}{l}\text { Completed, } \\
\text { published results }\end{array}$ \\
\hline Pirfenidone & $\begin{array}{l}\text { EudraCT 2014- } \\
000861-32 \\
\text { DRKS00009822 } \\
\text { (RELIEF) }\end{array}$ & $\begin{array}{l}\text { Phase II, randomized, } \\
\text { double blind, placebo- } \\
\text { controlled }\end{array}$ & $\mathrm{cHP}$ & $\begin{array}{l}\text { Efficacy and } \\
\text { safety }\end{array}$ & $\begin{array}{l}\text { Absolute change in } \% \\
\text { FVC from baseline } \\
\text { to week } 48\end{array}$ & Completed \\
\hline Pirfenidone & NCT02958917 & $\begin{array}{l}\text { Phase II, randomized, } \\
\text { double blind, placebo- } \\
\text { controlled }\end{array}$ & $\mathrm{cHP}$ & $\begin{array}{l}\text { Efficacy and } \\
\text { Safety }\end{array}$ & $\begin{array}{l}\text { Mean change in } \% \\
\text { FVC from baseline } \\
\text { to week } 52\end{array}$ & Ongoing \\
\hline
\end{tabular}

cHP: chronic hypersensitivity pneumonitis; ILDs: interstitial lung diseases; FVC: forced vital capacity. 
the lung injury causing agent is, fibrotic ILDs show similarities in disease presentation, behavior and also in the pathogenic process underlying the fibrotic process (Figure 1), which usually drives to irreversible loss of epithelial or endothelial barrier integrity, destruction of the lung architecture and loss of lung function ${ }^{82}$. Some authors took the moves from this assumption to test effectiveness of anti-fibrotic drugs in this cluster of diseases (Table 1).

Recently the results of phase III randomized placebo-controlled clinical trial-the INBUILD study (NCT02999178) were released and opened the doors to the safe use of nintedanib, an intracellular tyrosine kinase inhibitor, for fibrosing $\mathrm{ILDs}^{83}$. Flaherty et al. ${ }^{83}$ showed that nintedanib was effective in reducing the annual rate of FVC decline when compared to placebo in a cohort of 663 subjects. Patients with cHP represented $26 \%$ of the enrolled population, turning this a fundamental study for the management of this condition.

An open-label proof of concept study (NCT02496182) explored the efficacy of pirfenidone as add-on therapy to immunosuppressant in $\mathrm{cHP}^{84}$. Besides not showing improvement of lung function test parameters, there was a significant St. George Respiratory Questionnaire's total score improvement in the pirfenidone group. Addition of pirfenidone seems to have a tolerable safety profile and promising results in cHP patients.

Some other randomized clinical trials (RCT) exploring the effects of pirfenidone on cHP are on their way. A phase II placebo-controlled randomized controlled trial-the RELIEF study (EudraCT 2014-000861-32 DRKS00009822) - will soon explore the efficacy of pirfenidone in fibrosing ILDs and cHP is recognized as one of the inclusion criteria. Another phase II study (NCT02958917) is going to explore the effect of full dose pirfenidone in cHP patients ${ }^{85}$.

Lung transplant may be a resolutive treatment in cHP at its last stages of disease, such as in other ILDs.

\section{Conclusion}

HP remains a challenging condition to diagnose and manage because of its heterogenous clinical, radiologic, histologic and functional features. Lots of efforts are put in making order in the ILD field, but HP remains still a foggy region—even if it is the third most common ILD.

Even if in the last decade the interest around HP was constantly growing, neither internationally accepted classification nor guidelines based on international consensus for both diagnosis and clinical management are available for this disease. Several classification proposals and diagnostic models were advanced by different groups but still have not received any prospective validation. The scientific community is anxiously waiting for the guidelines supported by the ATS and ACCP that are on the line and would facilitate the design of the next clinical studies.

Diagnosis is particularly tricky in the latest stages of cHP when it may be confounded with IPF also in expert contests. MDT meetings play a pivotal role both in the diagnostic process and in the decision making and patient management.

Immunosuppressant therapy, which - together with antigen avoidance-is effective on aHP, is now flanked by the evidence of the effectiveness of nintedanib in reducing the rate of lung function decline in cHP. Other studies about pirfenidone use in $\mathrm{HP}$ are ongoing.

However, several questions about this condition remain still unanswered and there is plenty of room for more studies to come and focus their attention on different aspects and pitfalls of HP.

\section{Authors' Contributions}

Conceptualization: Leone PM, Richeldi L. Writing - original draft preparation: Leone PM. Writing - review and editing: Leone PM, Richeldi L. Approval of final manuscript: all authors.

\section{Conflicts of Interest}

Dr. Leone has nothing to disclose. Prof. Richeldi reports grants from Roche and Boehringer Ingelheim, personal fees from Boehringer Ingelheim, Roche, Biogen, FibroGen, SanofiAventis, Anthera, Promedior, ImmuneWorks, Asahi-Kasei, Bayer, Celgene, RespiVant, Nitto, Bristol Myers Squibb, Prometic, Pliant Therapeutics, Toray, Global Blood Therapeutics, Zambon, Veracyte, Acceleron, CSL Behring, outside of the submitted work

\section{Funding}

No funding to declare.

\section{References}

1. King TE Jr. Clinical advances in the diagnosis and therapy of the interstitial lung diseases. Am J Respir Crit Care Med 2005; 172:268-79

2. Hyldgaard C, Hilberg O, Muller A, Bendstrup E. A cohort study of interstitial lung diseases in central Denmark. Respir Med 2014;108:793-9.

3. Mohr LC. Hypersensitivity pneumonitis. Curr Opin Pulm Med 2004;10:401-11.

4. Johansson E, Boivin GP, Yadav JS. Early immunopathological events in acute model of mycobacterial hypersensitivity pneumonitis in mice. J Immunotoxicol 2017;14:77-88. 
5. Okamoto T, Miyazaki Y, Ogura T, Chida K, Kohno N, Kohno S, et al. Nationwide epidemiological survey of chronic hypersensitivity pneumonitis in Japan. Respir Investig 2013;51:1919.

6. Fernandez Perez ER, Kong AM, Raimundo K, Koelsch TL, Kulkarni R, Cole AL. Epidemiology of hypersensitivity pneumonitis among an insured population in the United States: a claims-based cohort analysis. Ann Am Thorac Soc 2018;15: 460-9.

7. Ley B, Collard HR, King TE Jr. Clinical course and prediction of survival in idiopathic pulmonary fibrosis. Am J Respir Crit Care Med 2011;183:431-40.

8. Martinez FJ, Collard HR, Pardo A, Raghu G, Richeldi L, Selman M, et al. Idiopathic pulmonary fibrosis. Nat Rev Dis Primers 2017;3:17074.

9. Noone A, Howlader N, Krapcho M, Miller D, Brest A, Yu M, et al. SEER cancer statistics review (CST) 1975-2015 [Internet]. Bethesda, MD: National Cancer Institute; 2018 [cited 2019 Dec 10]. Available from: https://seer.cancer.gov/csr/1975_2015/.

10. Morell F, Villar A, Montero MA, Munoz X, Colby TV, Pipvath S, et al. Chronic hypersensitivity pneumonitis in patients diagnosed with idiopathic pulmonary fibrosis: a prospective casecohort study. Lancet Respir Med 2013;1:685-94.

11. Thomeer MJ, Costabe U, Rizzato G, Poletti V, Demedts M. Comparison of registries of interstitial lung diseases in three European countries. Eur Respir J Suppl 2001;32:114s-8s.

12. Solaymani-Dodaran M, West J, Smith C, Hubbard R. Extrinsic allergic alveolitis: incidence and mortality in the general population. QJM 2007;100:233-7.

13. Barber CM, Wiggans RE, Carder M, Agius R. Epidemiology of occupational hypersensitivity pneumonitis; reports from the SWORD scheme in the UK from 1996 to 2015. Occup Environ Med 2017;74:528-30.

14. Buchvald F, Petersen BL, Damgaard K, Deterding R, Langston C, Fan LL, et al. Frequency, treatment, and functional outcome in children with hypersensitivity pneumonitis. Pediatr Pulmonol 2011;46:1098-107.

15. Sommerfeld CG, Weiner DJ, Nowalk A, Larkin A. Hypersensitivity pneumonitis and acute respiratory distress syndrome from E-cigarette use. Pediatrics 2018;141:e20163927.

16. Selman M. Hypersensitivity pneumonitis. In: Schwarz M, King TE Jr, editors. Interstitial lung disease. 5th ed. Shelton, CT: People's Medical Publishing House-USA; 2011. p. 597625.

17. Ohtsuka Y, Munakata M, Tanimura K, Ukita H, Kusaka H, Masaki Y, et al. Smoking promotes insidious and chronic farmer's lung disease, and deteriorates the clinical outcome. Intern Med 1995;34:966-71.

18. Camarena A, Aquino-Galvez A, Falfan-Valencia R, Sanchez G, Montano M, Ramos C, et al. PSMB8 (LMP7) but not PSMB9 (LMP2) gene polymorphisms are associated to pigeon breeder's hypersensitivity pneumonitis. Respir Med 2010;104:88994.
19. Aquino-Galvez A, Camarena A, Montano M, Juarez A, Zamora AC, Gonzalez-Avila G, et al. Transporter associated with antigen processing (TAP) 1 gene polymorphisms in patients with hypersensitivity pneumonitis. Exp Mol Pathol 2008;84: 173-7.

20. Fink JN, Ortega HG, Reynolds HY, Cormier YF, Fan LL, Franks TJ, et al. Needs and opportunities for research in hypersensitivity pneumonitis. Am J Respir Crit Care Med 2005;171:7928.

21. Agostini C, Trentin L, Facco M, Semenzato G. New aspects of hypersensitivity pneumonitis. Curr Opin Pulm Med 2004;10: 378-82.

22. Lopez M, Salvaggio JE. Epidemiology of hypersensitivity pneumonitis/allergic alveolitis. Monogr Allergy 1987;21:7086.

23. Selman M, Pardo A, King TE Jr. Hypersensitivity pneumonitis: insights in diagnosis and pathobiology. Am J Respir Crit Care Med 2012;186:314-24.

24. Salisbury ML, Myers JL, Belloli EA, Kazerooni EA, Martinez FJ, Flaherty KR. Diagnosis and treatment of fibrotic hypersensitivity pneumonia: where we stand and where we need to go. Am J Respir Crit Care Med 2017;196:690-9.

25. Vasakova M, Morell F, Walsh S, Leslie K, Raghu G. Hypersensitivity pneumonitis: perspectives in diagnosis and management. Am J Respir Crit Care Med 2017;196:680-9.

26. Cottin V, Hirani NA, Hotchkin DL, Nambiar AM, Ogura T, Otaola M, et al. Presentation, diagnosis and clinical course of the spectrum of progressive-fibrosing interstitial lung diseases. Eur Respir Rev 2018;27:180076.

27. Fernandez Perez ER, Swigris JJ, Forssen AV, Tourin O, Solomon JJ, Huie TJ, et al. Identifying an inciting antigen is associated with improved survival in patients with chronic hypersensitivity pneumonitis. Chest 2013;144:1644-51.

28. Morisset J, Johannson KA, Jones KD, Wolters PJ, Collard HR, Walsh SL, et al. Identification of diagnostic criteria for chronic hypersensitivity pneumonitis: an international modified Delphi survey. Am J Respir Crit Care Med 2018;197:1036-44.

29. Ojanguren I, Morell F, Ramon MA, Villar A, Romero C, Cruz MJ, et al. Long-term outcomes in chronic hypersensitivity pneumonitis. Allergy 2019;74:944-52.

30. Soumagne T, Dalphin JC. Current and emerging techniques for the diagnosis of hypersensitivity pneumonitis. Expert Rev Respir Med 2018;12:493-507.

31. Cormier Y, Belanger J, Tardif A, Leblanc P, Laviolette M. Relationships between radiographic change, pulmonary function, and bronchoalveolar lavage fluid lymphocytes in farmer's lung disease. Thorax 1986;41:28-33.

32. Kokkarinen JI, Tukiainen HO, Terho EO. Recovery of pulmonary function in farmer's lung: a five-year follow-up study. Am Rev Respir Dis 1993;147:793-6.

33. Gimenez A, Storrer K, Kuranishi L, Soares MR, Ferreira RG, Pereira CA. Change in FVC and survival in chronic fibrotic hypersensitivity pneumonitis. Thorax 2018;73:391-2. 
34. Dias OM, Baldi BG, Pennati F, Aliverti A, Chate RC, Sawamura MV, et al. Computed tomography in hypersensitivity pneumonitis: main findings, differential diagnosis and pitfalls. Expert Rev Respir Med 2018;12:5-13.

35. Schwaiblmair M, Beinert T, Vogelmeier C, Fruhmann G. Cardiopulmonary exercise testing following hay exposure challenge in farmer's lung. Eur Respir J 1997;10:2360-5.

36. Dias OM, Baldi BG, Ferreira JG, Cardenas LZ, Pennati F, Salito $\mathrm{C}$, et al. Mechanisms of exercise limitation in patients with chronic hypersensitivity pneumonitis. ERJ Open Res 2018;4: 00043-2018.

37. Lacasse Y, Selman M, Costabel U, Dalphin JC, Ando M, Morell F, et al. Clinical diagnosis of hypersensitivity pneumonitis. Am J Respir Crit Care Med 2003;168:952-8.

38. Chong BJ, Kanne JP, Chung JH. Headcheese sign. J Thorac Imaging 2014;29:W13.

39. Kligerman SJ, Henry T, Lin CT, Franks TJ, Galvin JR. Mosaic attenuation: etiology, methods of differentiation, and pitfalls. Radiographics 2015;35:1360-80.

40. Lynch DA, Newell JD, Logan PM, King TE Jr, Muller NL. Can CT distinguish hypersensitivity pneumonitis from idiopathic pulmonary fibrosis? AJR Am J Roentgenol 1995;165:807-11.

41. Silva CI, Muller NL, Lynch DA, Curran-Everett D, Brown KK, Lee KS, et al. Chronic hypersensitivity pneumonitis: differentiation from idiopathic pulmonary fibrosis and nonspecific interstitial pneumonia by using thin-section CT. Radiology 2008;246:288-97.

42. Barnett J, Molyneaux PL, Rawal B, Abdullah R, Hare SS, Vancheeswaran R, et al. Variable utility of mosaic attenuation to distinguish fibrotic hypersensitivity pneumonitis from idiopathic pulmonary fibrosis. Eur Respir J 2019;54:1900531.

43. Soumagne T, Chardon ML, Dournes G, Laurent L, Degano B, Laurent F, et al. Emphysema in active farmer's lung disease. PLoS One 2017;12:e0178263.

44. Franquet T, Hansell DM, Senbanjo T, Remy-Jardin M, Muller NL. Lung cysts in subacute hypersensitivity pneumonitis. J Comput Assist Tomogr 2003;27:475-8.

45. Salisbury ML, Gross BH, Chughtai A, Sayyouh M, Kazerooni EA, Bartholmai BJ, et al. Development and validation of a radiological diagnosis model for hypersensitivity pneumonitis. Eur Respir J 2018;52:1800443.

46. Walsh SL, Richeldi L. Demystifying fibrotic hypersensitivity pneumonitis diagnosis: it's all about shades of grey. Eur Respir J 2019;54:1900906.

47. Chung JH, Zhan X, Cao M, Koelsch TL, Manjarres DC, Brown KK, et al. Presence of air trapping and mosaic attenuation on chest computed tomography predicts survival in chronic hypersensitivity pneumonitis. Ann Am Thorac Soc 2017;14:1533-8.

48. Salisbury ML, Gu T, Murray S, Gross BH, Chughtai A, Sayyouh M, et al. Hypersensitivity pneumonitis: radiologic phenotypes are associated with distinct survival time and pulmonary function trajectory. Chest 2019;155:699-711.
49. Lynch DA. CT phenotypes in hpersensitivity pneumonitis. Chest 2019;155:655-6.

50. Jacob J, Bartholmai BJ, Egashira R, Brun AL, Rajagopalan S, Karwoski R, et al. Chronic hypersensitivity pneumonitis: identification of key prognostic determinants using automated CT analysis. BMC Pulm Med 2017;17:81.

51. Raghu G, Remy-Jardin M, Myers JL, Richeldi L, Ryerson CJ, Lederer DJ, et al. Diagnosis of idiopathic pulmonary fibrosis: an oficial ATS/ERS/JRS/ALAT clinical practice guideline. Am J Respir Crit Care Med 2018;198:e44-68.

52. Meyer KC, Raghu G, Baughman RP, Brown KK, Costabel U, du Bois RM, et al. An official American Thoracic Society clinical practice guideline: the clinical utility of bronchoalveolar lavage cellular analysis in interstitial lung disease. Am J Respir Crit Care Med 2012;185:1004-14.

53. Ohtani Y, Saiki S, Kitaichi M, Usui Y, Inase N, Costabel U, et al. Chronic bird fancier's lung: histopathological and clinical correlation: an application of the 2002 ATS/ERS consensus classification of the idiopathic interstitial pneumonias. Thorax 2005;60:665-71.

54. Santos V, Martins N, Sousa C, Jacob M, Padrao E, Melo N, et al. Hypersensitivity pneumonitis: main features characterization in a Portuguese cohort. Pulmonology 2019 Oct 29 [Epub]. https://doi.org/10.1016/j.pulmoe.2019.09.004.

55. Vourlekis JS, Schwarz MI, Cherniack RM, Curran-Everett D, Cool CD, Tuder RM, et al. The effect of pulmonary fibrosis on survival in patients with hypersensitivity pneumonitis. Am J Med 2004;116:662-8.

56. Fireman E, Vardinon N, Burke M, Spizer S, Levin S, Endler A, et al. Predictive value of response to treatment of T-lymphocyte subpopulations in idiopathic pulmonary fibrosis. Eur Respir J 1998;11:706-11.

57. Ohshimo S, Bonella F, Cui A, Beume M, Kohno N, Guzman J, et al. Significance of bronchoalveolar lavage for the diagnosis of idiopathic pulmonary fibrosis. Am J Respir Crit Care Med 2009;179:1043-7.

58. Patel AM, Ryu JH, Reed CE. Hypersensitivity pneumonitis: current concepts and future questions. J Allergy Clin Immunol 2001;108:661-70.

59. Barrera L, Mendoza F, Zuniga J, Estrada A, Zamora AC, Melendro EI, et al. Functional diversity of T-cell subpopulations in subacute and chronic hypersensitivity pneumonitis. Am J Respir Crit Care Med 2008;177:44-55.

60. Myers JL. Hypersensitivity pneumonia: the role of lung biopsy in diagnosis and management. Mod Pathol 2012;25 Suppl 1:S58-67.

61. Sharp C, McCabe M, Adamali H, Medford AR. Use of transbronchial cryobiopsy in the diagnosis of interstitial lung disease: a systematic review and cost analysis. QJM 2017;110: 207-14.

62. Iftikhar IH, Alghothani L, Sardi A, Berkowitz D, Musani AI. Transbronchial lung cryobiopsy and video-assisted thoracoscopic lung biopsy in the diagnosis of diffuse parenchymal 
lung disease: a meta-analysis of diagnostic test accuracy. Ann Am Thorac Soc 2017;14:1197-211.

63. Grunes D, Beasley MB. Hypersensitivity pneumonitis: a review and update of histologic findings. J Clin Pathol 2013;66: 888-95.

64. Miller R, Allen TC, Barrios RJ, Beasley MB, Burke L, Cagle PT, et al. Hypersensitivity pneumonitis A perspective from members of the Pulmonary Pathology Society. Arch Pathol Lab Med 2018;142:120-6.

65. Castonguay MC, Ryu JH, Yi ES, Tazelaar HD. Granulomas and giant cells in hypersensitivity pneumonitis. Hum Pathol 2015;46:607-13.

66. Wang P, Jones KD, Urisman A, Elicker BM, Urbania T, Johannson $\mathrm{KA}$, et al. Pathologic findings and prognosis in a large prospective cohort of chronic hypersensitivity pneumonitis. Chest 2017;152:502-9.

67. Johannson KA, Elicker BM, Vittinghoff E, Assayag D, de Boer $\mathrm{K}$, Golden JA, et al. A diagnostic model for chronic hypersensitivity pneumonitis. Thorax 2016;71:951-4.

68. Molyneaux PL, Maher TM. Time for an international consensus on hypersensitivity pneumonitis. A Call to Arms. Am J Respir Crit Care Med 2017;196:665-6.

69. Swigris J. DELPHIning diagnostic criteria for chronic hypersensitivity pneumonitis. Am J Respir Crit Care Med 2018;197: 980-1.

70. Fernandez Perez ER. Diagnostic decision-making in hypersensitivity pneumonitis: toward a consensus statement. Am J Respir Crit Care Med 2018;197:1646-7.

71. Takei R, Yamano Y, Kataoka K, Yokoyama T, Matsuda T, Kimura T, et al. Usefulness of new diagnostic criteria for chronic hypersensitivity pneumonitis established on the basis of a Delphi survey: a Japanese cohort study. Respir Investig 2020;58:52-8.

72. Walsh SL, Wells AU, Desai SR, Poletti V, Piciucchi S, Dubini A, et al. Multicentre evaluation of multidisciplinary team meeting agreement on diagnosis in diffuse parenchymal lung disease: a case-cohort study. Lancet Respir Med 2016;4:557-65.

73. Lynch DA, Sverzellati N, Travis WD, Brown KK, Colby TV, Galvin JR, et al. Diagnostic criteria for idiopathic pulmonary fibrosis: a Fleischner Society White Paper. Lancet Respir Med 2018;6:138-53.

74. Vasakova M, Morell F, Raghu G. Reply to Fernandez Perez: diagnostic decision-making in hypersensitivity pneumonitis: toward a consensus statement. Am J Respir Crit Care Med
2018;197:1648.

75. Cormier Y, Desmeule M. Treatment of hypersensitivity pneumonitis: contact avoidance versus corticosteroid treatment. Can Respir J 1994;1:223-8.

76. De Sadeleer LJ, Hermans F, De Dycker E, Yserbyt J, Verschakelen JA, Verbeken EK, et al. Effects of corticosteroid treatment and antigen avoidance in a large hypersensitivity pneumonitis cohort: a single-centre cohort study. J Clin Med 2018;8:E14.

77. Kokkarinen JI, Tukiainen HO, Terho EO. Effect of corticosteroid treatment on the recovery of pulmonary function in farmer's lung. Am Rev Respir Dis 1992;145:3-5.

78. Morisset J, Johannson KA, Vittinghoff E, Aravena C, Elicker $\mathrm{BM}$, Jones KD, et al. Use of mycophenolate mofetil or azathioprine for the management of chronic hypersensitivity pneumonitis. Chest 2017;151:619-25.

79. Adegunsoye A, Oldham JM, Fernandez Perez ER, Hamblin M, Patel N, Tener M, et al. Outcomes of immunosuppressive therapy in chronic hypersensitivity pneumonitis. ERJ Open Res 2017;3:00016-2017.

80. Morell F, Ojanguren I, Villar A, Ramon MA, Munoz X, Cruz MJ. Addition of rituximab to oral corticosteroids in the treatment of chronic hypersensitivity pneumonitis. Arch Bronconeumol 2019 Sep 7 [Epub]. https://doi.org/10.1016/ j.arbres.2019.07.013.

81. Carlsen KH, Leegaard J, Lund OD, Skjaervik H. Allergic alveolitis in a 12-year-old boy: treatment with budesonide nebulizing solution. Pediatr Pulmonol 1992;12:257-9.

82. Wuyts WA, Agostini C, Antoniou KM, Bouros D, Chambers RC, Cottin V, et al. The pathogenesis of pulmonary fibrosis: a moving target. Eur Respir J 2013;41:1207-18.

83. Flaherty KR, Wells AU, Cottin V, Devaraj A, Walsh SL, Inoue Y, et al. Nintedanib in progressive fibrosing interstitial lung diseases. N Engl J Med 2019;381:1718-27.

84. Mateos-Toledo H, Mejia-Avila M, Rodriguez-Barreto O, MejiaHurtado JG, Rojas-Serrano J, Estrada A, et al. An open-label study with pirfenidone on chronic hypersensitivity pneumonitis. Arch Bronconeumol 2019 Nov 26 [Epub]. https://doi. org/10.1016/j.arbres.2019.08.019.

85. Richeldi L, Varone F, Bergna M, de Andrade J, Falk J, Hallowell $\mathrm{R}$, et al. Pharmacological management of progressive-fibrosing interstitial lung diseases: a review of the current evidence. Eur Respir Rev 2018;27:180074. 